\section{Structural Studies on Polyvalent Compounds of Iodine}

Keith Prout* and N. Mark Stevens*, Alessandro Coda** and VitTorio Tazzoli**, and Robert A. Shaw*** and TürSen Demir***

* Chemical Crystallography Laboratory, 9, Parks Road, Oxford, U. K.

** Instituto di Cristallografia e Centro di Studio per la Cristallografia, Strutturale del C. N. R., Universitá di Pavia, Via Bassi, 4, 27100 Pavia, Italy.

*** Department of Chemistry, Birkbeck College, University of London, Malet Street, London, WC IE $7 \mathrm{HX}, \mathrm{U} . \mathrm{K}$.

(Z. Naturforsch. 31 b, 687-688 [1976]; received February 2, 1976)

Polyvalent Compounds, Iodine, X-ray, Bond-lengths Variations

The structures of 1-chloro-4,5-benziodoxalin-3-one (1) and 1,2-dichloro-4,5-benziodazalin-3-one (2) have been determined by $\mathrm{x}$-ray crystallography. These are compared with those of some compounds related to the former, as well as with $\mathrm{I}_{2} \mathrm{Cl}_{6}$. The bond of iodine to its exocyclic substituent appears to be very sensitive to environmental changes, as are the endocyclic iodine-oxygen and carbon-oxygen bonds (both where applicable) in the heterocyclic ring. The shapes of the molecules and their possible interactions with donor functions on adjacent molecules are discussed.

Relatively few polyvalent compounds of iodine have been investigated by means of diffractometric $\mathrm{X}$-ray crystallography. We report here the structures of 1-chloro-4,5-benziodoxalin-3-one (1) and 1,2dichloro-4,5-benziodazalin-3-one (2), the relevant molecular dimensions of which are given in the Figure, and compare these with some related compounds (3-6). The exocyclic I-Cl bond in the heterocycles (1), (2) and (3) ${ }^{1}$ increases in length in the order $\mathrm{Cl}<\mathrm{O}<\mathrm{N}$, of the atom in the heterocycle adjacent to iodine. This is in line with the general order of the balance of opposing inductive and mesomeric effects when these atoms are bonded to unsaturated systems. In compound 2 the nitrogen atom is trigonal planar. The exocyclic I-Cl bonds in the cyclic compound $\mathbf{3}$ are however shorter (2.38-2.39 $\AA$ ), than in a related acyclic compound (4) ${ }^{2,3}(2.49-2.50 \AA)$.

If we compare the exocyclic and endocyclic I-O bond-lengths in compounds $5^{3,4}$ and $6^{5,6}$, we note that the former is shorter and the latter longer in

Requests for reprints should be sent to Prof. Dr. R. A. Shaw or Dr. C. K. Prout, Department of Chemistry, Birkbeck College, Malet Street, London WC $1 E$ $7 H X$, England. the hydroxy compound (5), than the corresponding bonds in the acyloxy-derivatives (6). Lone-pair electron-density will be drawn towards the exocyclic carbonyl group (compounds 6), lengthening the exocyclic $\mathrm{I}-\mathrm{O}$ bond in this compared to 5 . The iodine atom is apparently a good transmitter of electronic effects, and the above causes the endocyclic I-O bond to be longer in the hydroxy compound (5) than in the acyloxy-derivatives (6). Indeed, transmission of this effect in the heterocyclic ring goes further and the endocyclic $\mathrm{C}-\mathrm{O}$ bond in $\mathbf{5}$ is shorter than in 6 , in line with this reasoning.

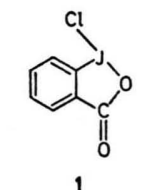<smiles>O=C1c2ccccc2I(Cl)N1Cl</smiles><smiles>Cl[Si](Cl)(Cl)Cl</smiles><smiles>ClI(Cl)c1ccccc1</smiles>

3<smiles></smiles><smiles>[R]C(=O)OI1OC(=O)c2ccccc21</smiles>

5

$\left[R=M e, C_{6} H_{4} \mathrm{~J}\right.$ ( $\alpha$-and $\beta$-forms) $] \longrightarrow$

In most of the heterocycles discussed here the $\mathrm{C}_{\text {aryl }}-\mathrm{C}_{\text {carbonyl }}$ bond is rather long.

In compounds 1, 2, 4-6 the three covalent bonds formed by iodine are approximately T-shaped in line with the prediction for five electron pairs ${ }^{7}$. The ends of the bar of the $\mathrm{T}$ are occupied by the most electronegative groups, as expected for trigonal bipyramids $\left(c f . \mathrm{ClF}_{3}{ }^{8}\right)$. It is noteworthy that the plane of the benzene ring in the acycle (4) is approximately perpendicular to the $\mathrm{Cl}-\mathrm{I}-\mathrm{Cl}$ system whereas in the fused heterocyclic systems $(\mathbf{1}, \mathbf{2}, \mathbf{5}$ and 6) the benzene ring and the iodine heterocycle sphere are strictly coplanar.

Closer examination of non-covalently bonded contacts suggests that in the crystals, all of these "formally" trivalent iodine compounds are either 4- or 5-coordinate (intra- and/or inter-molecular). Thus compound 4 has a close approach by a chlorine atom from a neighbouring molecule, giving rise to a square-planar arrangement (cf. $\mathrm{KICl}_{4}{ }^{9}$ ). Compound 2 by a similar chlorine donation is dimeric in pairs, with a similar stereochemical arrangement. Four of the ligands give always an approximately square planar arrangement. The fifth is not even approximately coplanar (contrast the recent structure of $\left[\mathrm{Te}(\mathrm{Etxan})_{3}\right]^{-}$anion, pentagonal planar $\left.{ }^{10}\right)$, but structures containing seven electron pairs are notoriously difficult to systematise. 

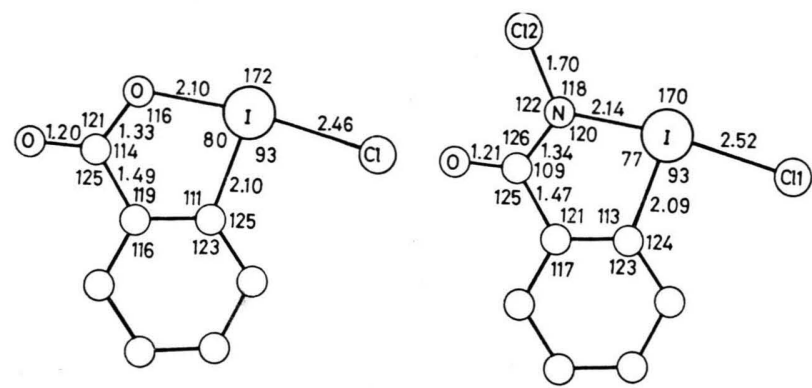

\section{Experimental}

Compound 1 was synthesised by a literature method, m.p. $172-174{ }^{\circ} \mathrm{C}$ (lit. ${ }^{11} 168-171^{\circ} \mathrm{C}$ ). Compound 2: ortho-iodobenzamide $(2.47 \mathrm{~g}, 0.01 \mathrm{~mol})$ was dissolved in methanol $(50 \mathrm{ml})$ and tert-butylhypochlorite $(3.8 \mathrm{~g}, 0.035 \mathrm{~mol})$ was added dropwise with stirring. In a few minutes a bright yellow precipitate was obtained, which was filtered, and

$1 \mathrm{~K} . \mathrm{H}$. BoswiJk and E. H. Wiebenga, Acta Crystallogr. 7, 417 [1954].

2 E. M. Archer and T. G. D. van Schalkwyk, Acta Crystallogr. 6, 88 [1953].

3 E. Schefter and W. Wolf, J. Pharm. Sci. 34, 104 [1965].

4 K. Prout and N. M. Stevens, unpublished.

5 J. Z. Goutgoutas and J. C. Clandy, J. Solid State Chem. 4, 226 [1972].

6 J. Z. Goutgoutas and J. C. Clandy, J. Solid State Chem. 4, 230 [1972]. air dried (yield $87 \%$ ). It was recrystallised from a mixture of $\mathrm{CCl}_{4} / \mathrm{CHCl}_{3}$ m.p. $184-189^{\circ} \mathrm{C}$ (lit. 12 $\left.178-181^{\circ} \mathrm{C}\right)$.

Crystal data: a) 1-chloro-4, 5-benziodoxalin-3-one, white monoclinic needles, $a=8.54(1), b=6.30(1)$, $c=14.90(2) \AA, \quad \beta=94.1(1)^{\circ} ;$ space group $\mathrm{P} 2_{1} / \mathrm{c}$ $\left(\mathrm{C}_{2 \mathrm{~h}}^{5}\right.$, No. 14). MoK $\alpha$ radiation, graphite monochromator, Hilger \& Watts four-circle diffractometer 1229 independent reflections. Final $R, 2.1 \%$ after full matrix anisotropic refinement, b) 1,2dichloro-4,5-benziodazalin-3-one orange-yellow monoclinic needles $a=25.041(7), \quad b=6.261(2)$, $c=5.777(2) \AA, \quad \beta=90.98(3)^{\circ}$; space group $\mathrm{P} 2 / 1 \mathrm{n}$ $\left(\mathrm{C}_{2 \mathrm{~h}}^{5}\right.$ No. 14, non-standard setting). MoK $a$ radiation, graphite monochromator Philips four-circle diffractometer 2911 independent reflections, final $R$ $4.15 \%$ after full matrix anisotropic least-squares refinement.

T. D. thanks TuRner and Newall for a Research Fellowship.

7 R. J. Gillespie and R. S. Nyholm, Quart. Rev. Chem. Soc. 11, 339 [1957].

8 R. D. Burbank and F. N. Bensey, J. Chem. Phys. 21, 602 [1953].

9 R. C. L. Mooney, Z. Krist. 98 A, 377 [1938].

10 B. F. Hoskins and C. D. Pannan, Chem. Commun. $1975,408$.

11 R. M. Keefer and L. J. Andrews, J. Amer. Chem. Soc. 81, 2374 [1959].

12 R. M. Keefer and L. J. Andrews, J. Amer. Chem. Soc. 81, 5329 [1959]. 